\title{
REVIEW
}

Open Access

\section{Role of non-statin lipid-lowering therapy in coronary atherosclerosis regression: a meta- analysis and meta-regression}

Walter Masson ${ }^{1,2}$, Martin Lobo ${ }^{1}$, Daniel Siniawski ${ }^{1,2}$, Graciela Molinero ${ }^{1}$, Gerardo Masson ${ }^{1}$, Melina Huerín ${ }^{1}$ and Juan Patricio Nogueira $2,3^{*}$ (i)

\begin{abstract}
Background: Several studies have investigated the association between non-statin lipid-lowering therapy and regression of atherosclerosis. However, these studies were mostly small and their results were not always robust. The objectives were: (1) to define if a dual lipid-lowering therapy (statin + non-statin drugs) is associated with coronary atherosclerosis regression, estimated by intravascular ultrasound (IVUS); (2) to assess the association between dual lipid-lowering-induced changes in low density lipoprotein cholesterol (LDL-C) and non-high-densitylipoprotein cholesterol (non-HDL-C) levels and atherosclerosis regression.

Methods: A meta-analysis including trials of non-statin lipid-lowering therapy, reporting LDL-C, non-HDL-C and total atheroma volume (TAV) with a minimum of 6 months of follow-up was performed. The primary endpoint was defined as the change in TAV measured from baseline to follow-up, comparing groups of subjects on statins alone versus combination of statin and non-statin drugs. The random-effects model and meta-regression were performed.

Results: Eight eligible trials of non-statin lipid-lowering drugs (1759 patients) were included. Overall, the dual lipidlowering therapy was associated with a significant reduction in TAV $\left[-4.0 \mathrm{~mm}^{3}(\mathrm{Cl} 95 \%-5.4\right.$ to -2.6$\left.\left.)\right] ; \mathrm{I}^{2}=0 \%\right]$. The findings were similar in the stratified analysis according to the lipid-lowering drug class (ezetimibe or PCSK9 inhibitors). In the meta-regression, a 10\% decrease in LDL-C or non-HDL-C levels, was associated, respectively, with $1.0 \mathrm{~mm}^{3}$ and $1.1 \mathrm{~mm}^{3}$ regressions in TAV.

Conclusion: These data suggests the addition of ezetimibe or PCSK9 inhibitors to statin therapy results in a significant regression of TAV.

Reduction of coronary atherosclerosis observed with non-statin lipid-lowering therapy is associated to the degree of LDL-C and non-HDL-C lowering. Therefore, it seems reasonable to achieve lipid goals according to cardiovascular risk and regardless of the lipid-lowering strategy used (statin monotherapy or dual treatment).
\end{abstract}

Keywords: Intravascular ultrasound, Coronary atherosclerosis plaque, Ezetimibe, PCSK9 inhibitors, Non-statin therapy, Atherosclerosis regression, Meta-analysis

\footnotetext{
* Correspondence: nogueirajuanpatricio@gmail.com

${ }^{2}$ Argentine Society of Lipids, Ambrosio Olmos 820, X5000JGQ Córdoba,

Argentina

${ }^{3}$ Av. Dr. Luis Gutniski 3200, 3600 Formosa, Argentina

Full list of author information is available at the end of the article
}

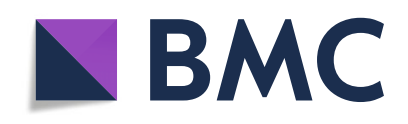

(- The Author(s). 2020 Open Access This article is licensed under a Creative Commons Attribution 4.0 International License, which permits use, sharing, adaptation, distribution and reproduction in any medium or format, as long as you give appropriate credit to the original author(s) and the source, provide a link to the Creative Commons licence, and indicate if changes were made. The images or other third party material in this article are included in the article's Creative Commons licence, unless indicated otherwise in a credit line to the material. If material is not included in the article's Creative Commons licence and your intended use is not permitted by statutory regulation or exceeds the permitted use, you will need to obtain permission directly from the copyright holder. To view a copy of this licence, visit http://creativecommons.org/licenses/by/4.0/. The Creative Commons Public Domain Dedication waiver (http://creativecommons.org/publicdomain/zero/1.0/) applies to the data made available in this article, unless otherwise stated in a credit line to the data. 


\section{Introduction}

Coronary plaque regression has a significant positive correlation with low density lipoprotein cholesterol (LDL-C) and non-high-density-lipoprotein cholesterol (non-HDL-C) reduction [1]. Multiple diagnostic methods have been used to assess the composition of atherosclerotic plaque. Coronary intravascular ultrasound (IVUS) has been used in most of the studies that evaluate the impact of pharmacological interventions on the progression/regression of atherosclerosis. On the other hand, the regression of atherosclerosis measure by IVUS has been a subrogated endpoint of clinical cardiovascular events [2, 3].

The use of statins has been and continues today to be the cornerstone of risk management of cardiovascular disease. The robust evidence showing a reduction of cardiovascular events has made statins essential in a variety of clinical conditions with elevated cardiovascular risk [4-6]. In the same way, several studies have demonstrated that statin therapy promotes coronary atheroma stabilization and regression in patients with acute coronary events or stable coronary disease [7-11].

Despite reductions in LDL-C with statins, many people still experience cardiovascular events (cardiovascular residual risk). Dual lipid-lowering therapy with ezetimibe or inhibitors of proprotein convertase subtilisin kexin type 9 (PCSK9) has been shown to be more effective than statin monotherapy in high-risk patients with coronary artery disease $[12,13]$. In recent years, many studies have investigated the reduction of LDL-C with nonstatin drugs and Its impact on atherosclerosis regression. However, the studies were mostly small and their results were not always robust [14-21]. A previously published meta-analysis showed an association between the regression of atheroma volume with the addition of ezetimibe [22]. Nevertheless, this study did not include a metaregression to assess the relationship between the decrease in lipid markers achieved with dual lipid-lowering therapy and plaque regression. Moreover, it didn't evaluate non-statin drugs such as PCSK9 inhibitors. The dual therapy would be successful if it reduces an adequate percentage in lipid levels and, consequently, attains regression in the volume of atherosclerotic plaque. The hypothesis of this investigation was that an additional decrease in cholesterol levels with a non-statin therapy would result in atherosclerosis regression, being greater with more intensive decrease in lipid levels. Therefore, the objectives of the present meta-analysis were: (1) to define if a more aggressive dual lipid-lowering therapy with non-statin drugs is associated with a regression in coronary atherosclerosis estimated by IVUS; (2) to assess the association between dual lipid-lowering-induced changes in LDL-C and non-HDL-C levels and regression of atherosclerosis.

\section{Material and methods}

\section{Data extraction and quality assessment}

This meta-analysis was performed according to the Preferred Reporting Items for Systematic Reviews and Meta-Analyses (PRISMA) guidelines for reporting systematic reviews [23]. A literature search was performed that identified clinical trials of non-statin drugs that are recommended by the current cholesterol guidelines based on the results of clinical trials that showed efficacy in the reduction of cardiovascular events, and published between January 1990 and January 2020 in English. Two independent reviewers searched the electronic PubMed/ MEDLINE, Embase and Cochrane Controlled Trials databases using the following terms: "endovascular ultrasound", "IVUS", "atherosclerosis regression", "lipidlowering therapy", "ezetimibe" and "PCSK9 inhibitors".

All the analyzed studies meet the following inclusion criteria: a) Comparisons of efficacy for a statin monotherapy versus statin plus non-statin therapy (ezetimibe or PCSK9 inhibitor therapy); b) Follow-up duration $\geq 6$ months; c) IVUS used as modality for measuring changes in atheroma volume; c) Reporting of change in atheroma between baseline and follow-up, expressed as mean delta total atheroma volume (TAV); d) Reporting the change in lipids values between baseline and followup.

The primary endpoint of the study was defined as the change in TAV measured from baseline to follow-up, comparing groups of subjects on statins alone versus combination of statin and non-statin drugs.

The dual therapy was used to investigate whether the additional decrease in LDL-C or non-HDL-C was associated with a regression in the volume of atheroma in the evaluated studies. Basal population risk is the main criterion by which treatment without statins should be considered;in that sense, all selected studies included high or very high cardiovascular risk patients. Only 3 studies evaluated in this meta-analysis determined as an inclusion criteria having a baseline level of LDL-C > $100 \mathrm{mg} / \mathrm{dl}$.

When the summary/dispersion measures used to report the difference in TAV between the arms were not mean and standard deviation, conversion tools previously suggested by the literature were used [24].

Potential risks of bias were evaluated, using the Cochrane tool developed for this purpose [25]. This tool assesses bias in different domains: random sequence generation (selection bias); allocation concealment (selection bias); blinding of participants and study staff (performance bias); blinding of outcome assessors (detection bias); incomplete results data (attrition bias); selective reporting of results (reporting bias); and other sources of bias. Each domain was rated as "High", "Low" or "Unclear" depending on the judgment of each author following the recommendations. 
Meta-analysis and meta-regression analyses

The summary effect of non-statin lipid- lowering drugs on the TAV was estimated. Exploratory meta-regression analyses were performed to examine the potential associations between C-LDL and non-HDL-C reduction and the effect sizes of non-statin lipid-lowering drugs on atheroma regression.

\section{Statistical analysis}

Measures of effect size were expressed as mean difference, and the $\mathrm{I}^{2}$ statistic was calculated to quantify between-trial heterogeneity and inconsistency. Because studies differ in their lipid-modifying regimens and effect sizes, a random-effects model was chosen. However, to assess the relationship between differences in LDL-C and non-HDL-C reduction and variations in mean difference of atheroma volume, a mixed-effects metaregression model was performed. To compare mean effects between subgroups, a $\mathrm{Z}$ test was used. The level of statistical significance was set at a two-tailed alpha of
0.05. Statistical analyses were performed using the $R$ software for statistical computing version 3.5.1 with additional specific packages [26].

\section{Sensitivity analyses}

Through this analysis, the results of the meta-analysis were replicated excluding in each step one of the studies included in the review. The analysis was considered robust when the results obtained were similar.

Analysis of publication bias: A funnel plot using the standard error (SE) for mean difference was created, and Begg and Mazumdar rank correlation were also performed. In addition, Egger's regression intercept tests were done.

\section{Results}

Eight eligible trials of non-statin lipid-lowering drugs, including 1759 patients, were identified and considered eligible for the analyses. There was a total of 879 subjects allocated to receive dual lipid-lowering therapy

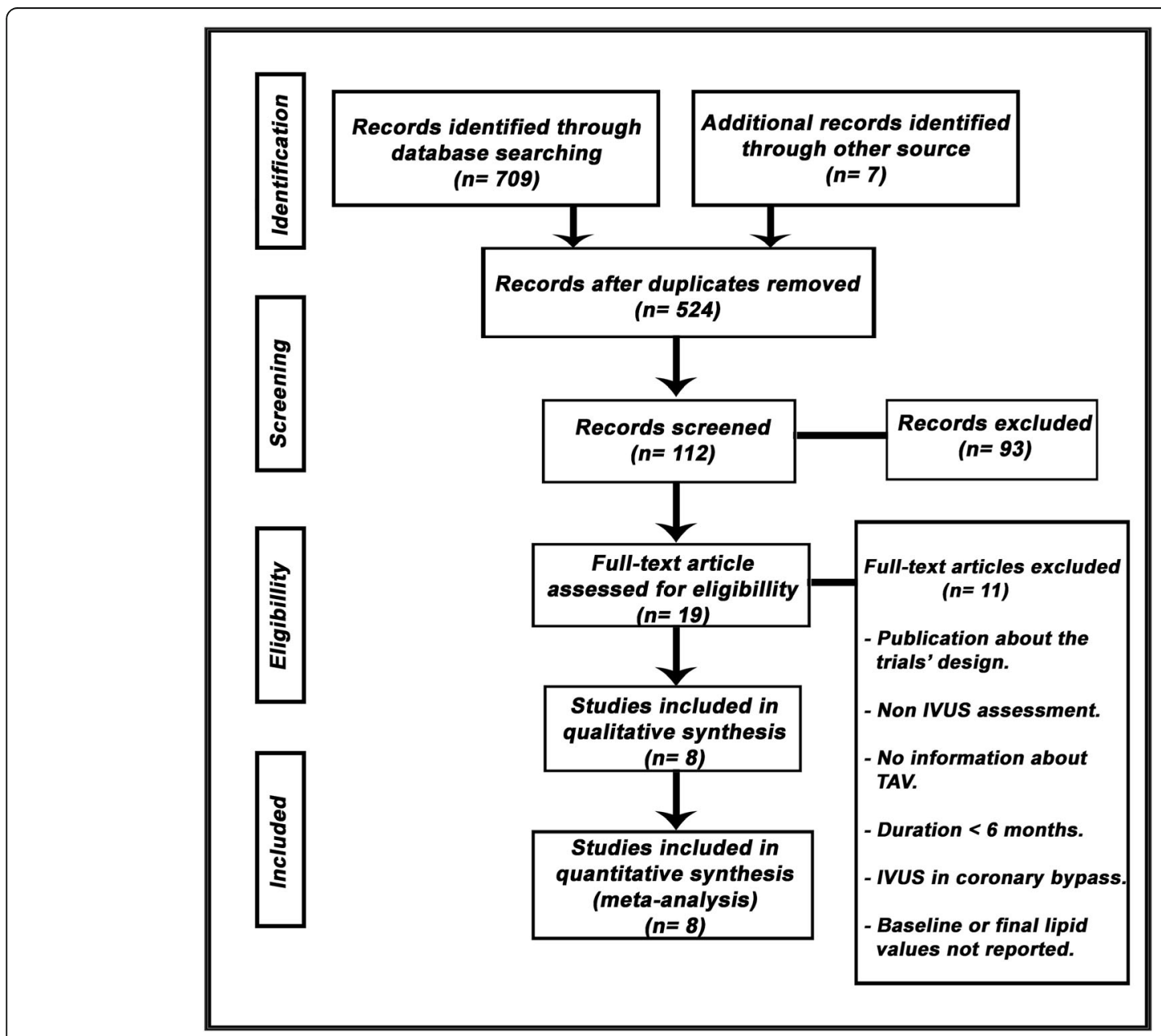

Fig. 1 Flow diagram of the study screening process. TAV: total ateroma volumen; IVUS: intravascular ultrasound 
(statin plus ezetimibe or PCSK9 inhibitors) and 880 subjects allocated to the respective control arms (statin monotherapy). A flow diagram of the study's screening process has been shown in Fig. 1.

Seven studies were randomized and all of the trials evaluated had a control arm. The quality of the studies evaluated can be seen in Fig. 2.

Three studies included patients with chronic coronary heart disease (HEAVEN, Masuda et al., GLAGOV) and other four studies evaluated subjects after an acute coronary syndrome (OCTIVUS, ZEUS, Hibi et al., ODYSSEY-J). The additional study accepted both options as inclusion criteria (PRECISE-IVUS). Six studies that evaluated the addition of ezetimibe and two studies that analyzed the additional effect of PCSK9 inhibitors were included. In studies that included patients with acute coronary syndrome, the IVUS measurement was performed in a different coronary segment than the culprit lesion.

The follow-up ranged between 6 and 19 months. The characteristics of the studies included in the analysis can be seen in Table 1 .

Overall, this meta-analysis showed that dual lipidlowering therapy was associated with a significant reduction in TAV $\left[-4.0 \mathrm{~mm}^{3}\right.$ (CI 95\% -5.4 to -2.6$\left.)\right] ; P<$ 0.0001; $\left.\mathrm{I}^{2}=0 \%\right]$ Fig. 3 .

In the stratified analysis according to the lipidlowering drug class, the findings were similar: (1) ezetimibe group: $\left[-4.0 \mathrm{~mm}^{3}\right.$ (CI 95\% -6.5 to -1.5$\left.)\right] ; P=$ $\left.0.0018 ; \mathrm{I}^{2}=18 \%\right]$; (2) PCSK9 inhibitor group: $\left[-3.9 \mathrm{~mm}^{3}\right.$ (CI 95\% -6.0 to - 1.7)]; $P<0.0001 ; \mathrm{I}^{2}=0 \%$ ] Fig. 3 .

In the meta-regression, the LDL-C reduction associated with dual lipid-lowering therapy was associated with a significant reduction in TAV $(P=0.0083)$.

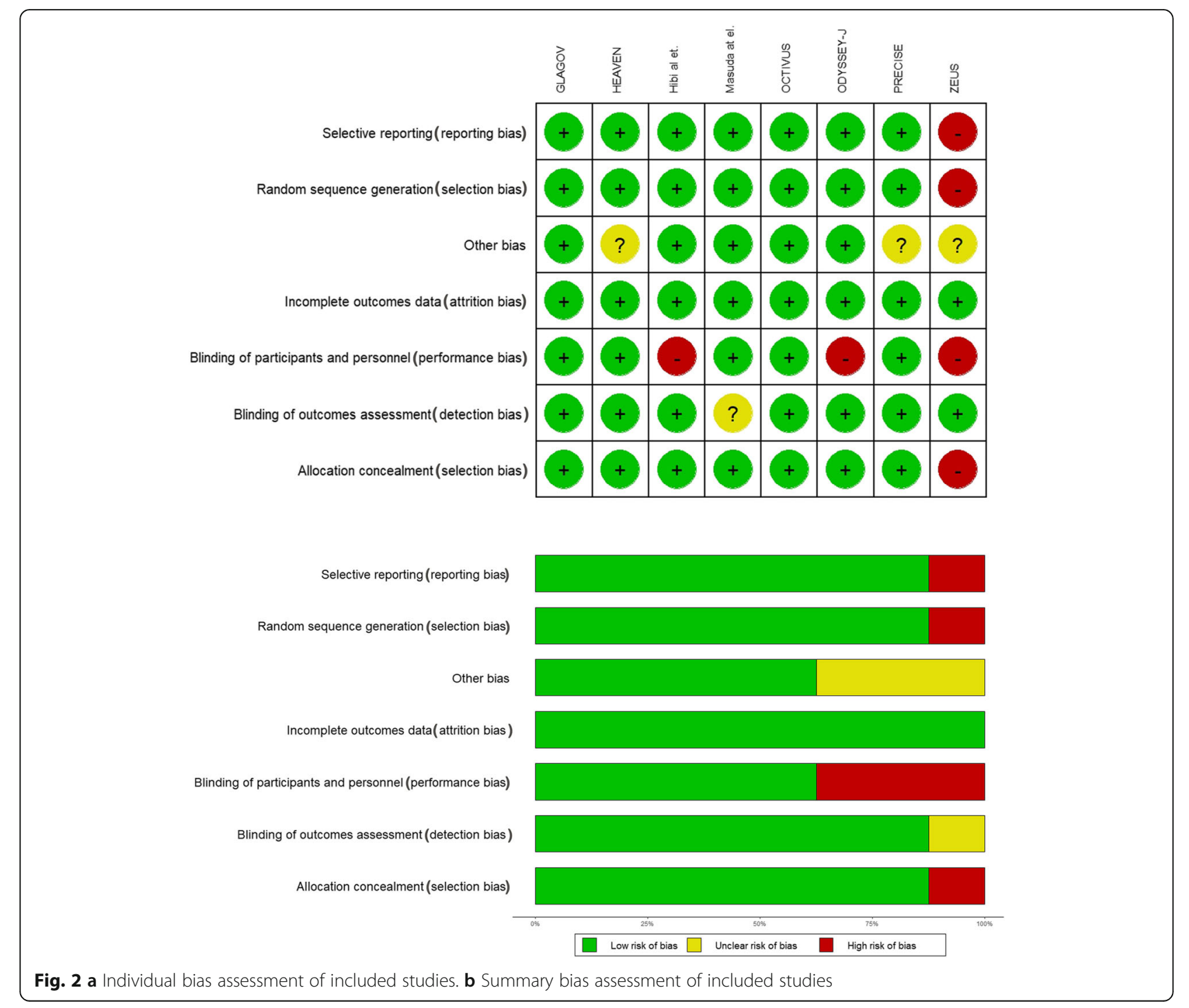


Table 1 Characteristics of the studies included in the analysis

\begin{tabular}{|c|c|c|c|c|c|c|c|c|c|c|c|c|}
\hline \multirow[t]{2}{*}{ Study } & \multirow{2}{*}{$\begin{array}{l}\text { Publication } \\
\text { year }\end{array}$} & \multirow[t]{2}{*}{ Population } & \multirow{2}{*}{$\begin{array}{l}\text { Follow- } \\
\text { up } \\
\text { (months) }\end{array}$} & \multirow[t]{2}{*}{ Design } & \multicolumn{4}{|c|}{ Dual lipid-lowering therapy } & \multicolumn{4}{|c|}{ Statin monotherapy } \\
\hline & & & & & $\bar{N}$ & Treatment & $\begin{array}{l}\text { Baseline } \\
\text { LDL-C }\end{array}$ & $\begin{array}{l}\text { Baseline } \\
\text { non- } \\
\text { HDL-C }\end{array}$ & $\bar{N}$ & Treatment & $\begin{array}{l}\text { Baseline } \\
\text { LDL-C }\end{array}$ & $\begin{array}{l}\text { Baseline } \\
\text { non- } \\
\text { HDL-C }\end{array}$ \\
\hline $\begin{array}{l}\text { HEAVEN } \\
{[14]}\end{array}$ & 2012 & SAP & 12 & $\begin{array}{l}\text { Single- } \\
\text { blinded. } \\
\text { RCT }\end{array}$ & 42 & $\begin{array}{l}\text { Atorvastatin } 80 \\
\text { mg/day + } \\
\text { Ezetimibe } 10 \text { mg/ } \\
\text { day }\end{array}$ & 119.9 & 143.1 & 47 & $\begin{array}{l}\text { Standard } \\
\text { statin } \\
\text { therapy }\end{array}$ & 104.4 & 131.5 \\
\hline $\begin{array}{l}\text { OCTIVUS } \\
{[15]}\end{array}$ & 2016 & ACS & 11.6 & $\begin{array}{l}\text { Double- } \\
\text { blinded. } \\
\text { RCT }\end{array}$ & 39 & $\begin{array}{l}\text { Atorvastatin } 80 \\
\text { mg/day + } \\
\text { Ezetimibe } 10 \text { mg/ } \\
\text { day }\end{array}$ & 142.9 & 162.1 & 41 & $\begin{array}{l}\text { Atorvastatin } \\
80 \text { mg/day + } \\
\text { Placebo }\end{array}$ & 158.3 & 177.6 \\
\hline ZEUS [16] & 2014 & ACS & 6 & $\begin{array}{l}\text { Open } \\
\text { label. } \\
\text { Non RCT }\end{array}$ & 50 & $\begin{array}{l}\text { Atorvastatin } 20 \\
\text { mg/day + } \\
\text { Ezetimibe } 10 \text { mg/ } \\
\text { day }\end{array}$ & 116.2 & 137.5 & 45 & $\begin{array}{l}\text { Atorvastatin } \\
20 \mathrm{mg} / \text { day }\end{array}$ & 114.3 & 137.8 \\
\hline $\begin{array}{l}\text { Hibi et al. } \\
{[17]}\end{array}$ & 2018 & ACS & 10 & $\begin{array}{l}\text { Open } \\
\text { label. } \\
\text { RCT }\end{array}$ & 50 & $\begin{array}{l}\text { Pitavastatin } 2 \text { mg/ } \\
\text { day + Ezetimibe } \\
10 \text { mg/day }\end{array}$ & 123.0 & 146.0 & 53 & $\begin{array}{l}\text { Pitavastatin } \\
2 \mathrm{mg} / \text { day }\end{array}$ & 126.0 & 150.0 \\
\hline $\begin{array}{l}\text { PRECISE } \\
{[18]}\end{array}$ & 2015 & $\begin{array}{l}\text { ACS/SAP } \\
\text { Basal LDL- } \\
C>100 \mathrm{mg} / \\
\text { dl }\end{array}$ & 10.1 & $\begin{array}{l}\text { Single- } \\
\text { blinded. } \\
\text { RCT }\end{array}$ & 100 & $\begin{array}{l}\text { Atorvastatin }{ }^{a}+ \\
\text { Ezetimibe } 10 \mathrm{mg} / \\
\text { day }\end{array}$ & 109.8 & 136.2 & 102 & Atorvastatin ${ }^{a}$ & 108.3 & 132.7 \\
\hline $\begin{array}{l}\text { Masuda } \\
\text { et al. [19] }\end{array}$ & 2015 & $\begin{array}{l}\text { SAP Basal } \\
\text { LDL-C }>100 \\
\mathrm{mg} / \mathrm{dl}\end{array}$ & 6 & $\begin{array}{l}\text { Open } \\
\text { label. } \\
\text { RCT }\end{array}$ & 21 & $\begin{array}{l}\text { Rosuvastatin } 5 \\
\text { mg/day + } \\
\text { Ezetimibe } 10 \text { mg/ } \\
\text { day }\end{array}$ & 131.8 & 151.4 & 19 & $\begin{array}{l}\text { Rosuvastatin } \\
5 \mathrm{mg} / \text { day }\end{array}$ & 123.0 & 146.2 \\
\hline $\begin{array}{l}\text { GLAGOV } \\
{[20]}\end{array}$ & 2016 & SAP & 19 & $\begin{array}{l}\text { Double- } \\
\text { blinded. } \\
\text { RCT }\end{array}$ & 484 & $\begin{array}{l}\text { Statin + } \\
\text { Evolucumab } 420 \\
\text { mg M }\end{array}$ & 92.6 & 119.4 & 484 & $\begin{array}{l}\text { Statin + } \\
\text { Placebo }\end{array}$ & 92.4 & 120.8 \\
\hline $\begin{array}{l}\text { ODYSSEY- } \\
J \text { [21] }\end{array}$ & 2019 & $\begin{array}{l}\text { ACS. Basal } \\
\text { LDL-C }>100 \\
\mathrm{mg} / \mathrm{dl}\end{array}$ & 9 & $\begin{array}{l}\text { Open } \\
\text { label. } \\
\text { RCT }\end{array}$ & 93 & $\begin{array}{l}\text { Statin }^{\text {b }} \\
\text { Alirocumab 75/ } \\
150 \text { mg Q2W }\end{array}$ & 97.9 & 124.1 & 89 & Statin $^{b}$ & 95.7 & 124.4 \\
\hline
\end{tabular}

ACS acute coronary syndrome, $M$ one monthly, Q2W every 2 weeks, $R C T$ randomized clinical trial, SAP stable angina pectoris

${ }^{a}$ Atorvastatin was increased by titration with the usual dose range with a treatment goal of $L D L-C<70 \mathrm{mg} / \mathrm{dl}$

bStandard-of-care

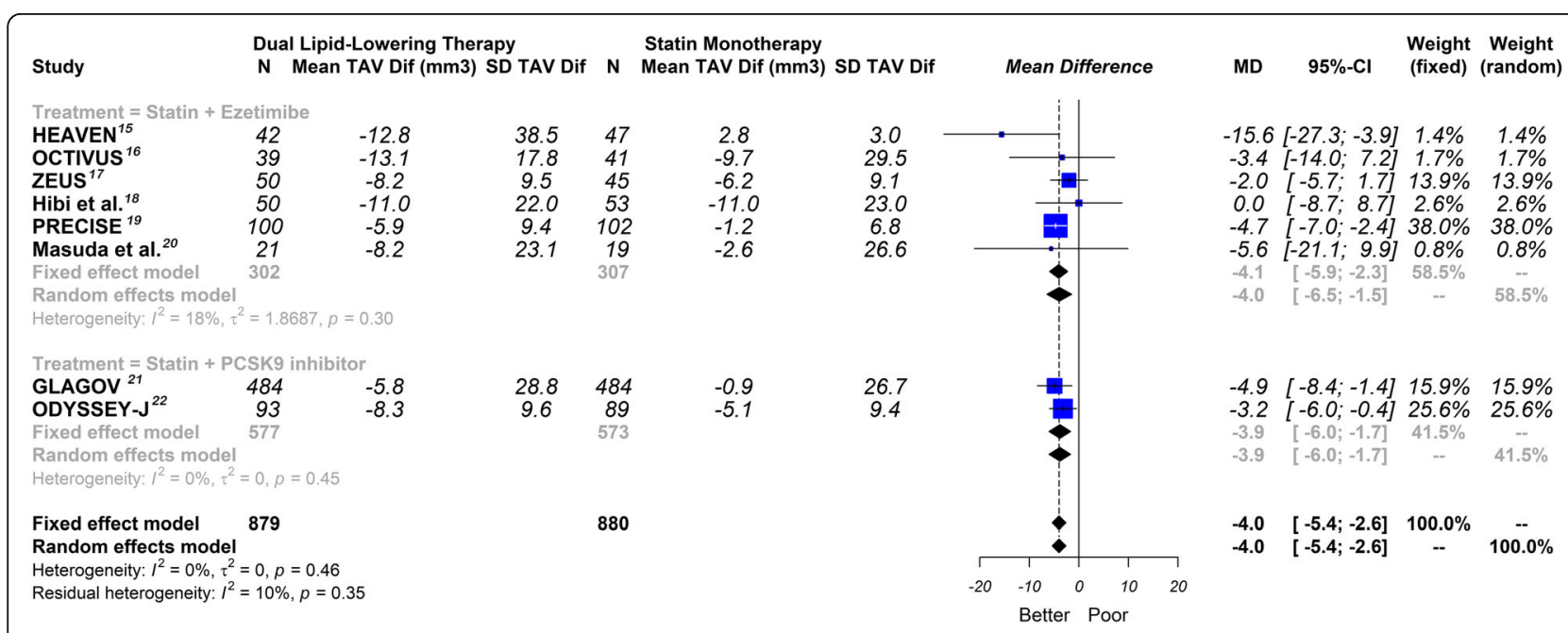

Fig. 3 Effect of non-statin lipid-lowering therapy on total atheroma volume. Global and subgroup drug analysis. Random effects, mean difference, 95\% confidence intervals (CI) and $\mathrm{I}^{2}$ statistics. TAV: total atheroma volume; Dif: difference 
Furthermore, when we analyzed the non-HDL-C, metaregression showed similar results $(P=0.0057)$. In addition, a $10 \%$ decrease in LDL-C or non-HDL-C levels, was associated, respectively, with $1.0 \mathrm{~mm}^{3}$ and $1.1 \mathrm{~mm}^{3}$ regressions in TAV. Figures 4 and 5 show metaregression analysis by lipids values reductions.

The funnel plot of standard error by mean difference of endpoints did not suggest publication bias Figure 6 . In the same way, Begg and Mazumdar's test for rank correlation gave a $P$ value of 0.8046 , not indicating possible publication bias. In addition, Egger's regression intercept tests gave a $P$ value of 0.6876 .

The sensitivity analysis showed that the results were robust Fig. 7 ..

\section{Discussion}

In this meta-analyses, dual lipid-lowering treatment (statin plus ezetimibe or PCSK9 inhibitors) compared with statin monotherapy was associated with greater reduction in TAV. The results were consistent in the global and lipid-lowering drugs subgroups analysis, suggesting that the decrease in LDL-C itself would be more relevant than the pharmacological mechanism that generates it. There is strong evidence of the relationship between LDL-C levels, the regression of atherosclerotic plaque and the reduction of cardiovascular events $[1,5]$. Statins play a role in plaque regression with reduction in lipid content. These medications stabilize atherosclerotic plaque with thickened fibrous layers and macrocalcification [8].

Ezetimibe, an inhibitor of the Niemann-Pick C1-like 1 cholesterol transporter, is a relatively new drug for LDLC-lowering therapy [27]. Combination therapy with a statin and ezetimibe produced better clinical outcomes than statin monotherapy in the IMPROVE-IT study
[12]. Similarly, PCSK9 inhibitors are new pharmacologic agents that have an incremental effect on lowering LDL$C$ in statin-treated patients, combined with an excellent safety profile [28]. In the recent FOURIER and ODYSSEY OUTCOMES trials, PCSK9 inhibition produced a relevant reduction in serum LDL-C levels by suppressing LDL-C receptor degradation and, consequently, has demonstrated clinical efficacy, in addition to statin therapy, in reducing cardiovascular events in patients with clinical evident atherosclerotic disease [13, 29].

The effect of lipid reduction on the atheroma plaque regression was mainly evaluated in statin trials. For example, one of the pioneering investigations, the REVERSAL study, showed regression of the statin-mediated coronary plaque when the decrease in LDL-C level exceeded $50 \%$ [30].

The role of ezetimibe in atherosclerosis regression was initially uncertain. The ENHANCE study did not find significant changes in the intima-media thickness in patients with familiar hypercholesterolemia treated by simvastatin with and without ezetimibe [31]. Nevertheless, beyond some methodological limitations of this study, the use of carotid ultrasound to assess the regression of atherosclerosis has been displaced by IVUS. A recent meta-analysis found no significant association between LDL-C reduction and progression of atherosclerosis estimated by carotid intima-media thickness [32].

Atherosclerotic plaque regression and conversion to a stable phenotype is possible with intensive statin therapy and can be demonstrated in patients using a variety of non-invasive and invasive imaging modalities [33]. The use of IVUS in the present analysis to evaluate atheroma volume is a globally established method to evaluate the vascular effect of lipid-lowering therapy. Previously, Mirzaee et al. showed that the addition of ezetimibe to statin

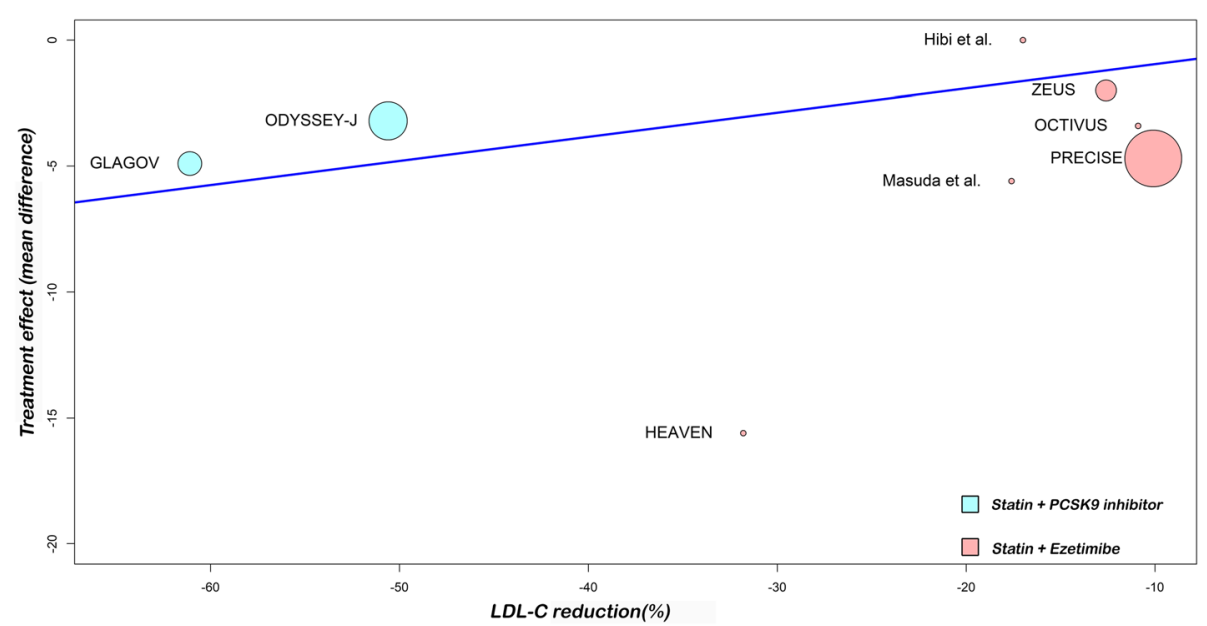

Fig. 4 Random-effects meta-regression analyses: Association between the difference in percentage LDL-C reduction among treatment arms and treatment effect (total atheroma volume regression) 


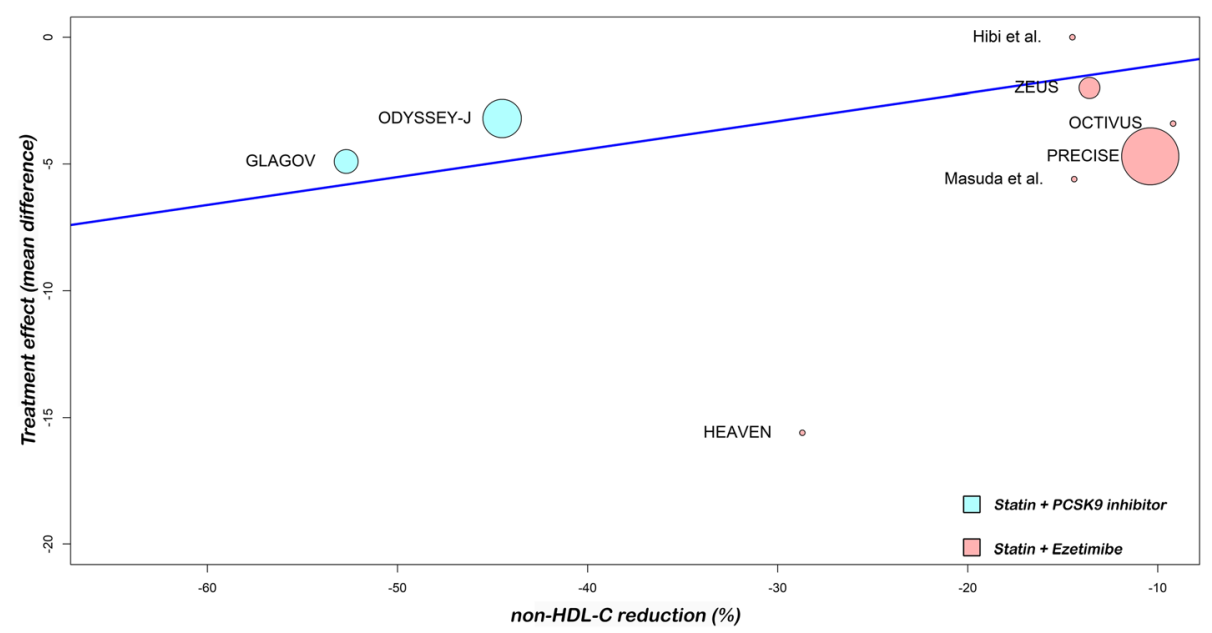

Fig. 5 Random-effects meta-regression analyses: Association between the difference in percentage non-HDL-C reduction among treatment arms and treatment effect (total atheroma volume regression)

therapy is effective in reducing total atheroma volume assessed by IVUS [22]. However, they did not evaluate other non-statin drugs such as PCSK9 inhibitors. Experimental studies have suggested that PCSK9 might directly promote inflammatory processes contributing to atherosclerosis [34]. Likewise, although it is widely accepted that the association between PCSK9 and atherosclerosis is dependent on PCSK9-mediated modulation of LDL metabolism, there is a lot of evidence suggesting that PCSK9 may also exert direct cholesterol-independent pro-atherosclerotic effects [35]. However, a recent meta- analysis failed to demonstrate an effect of PCSK9 inhibitors on high sensitivity C-reactive protein concentrations. This led to questioning the impact of these drugs on systemic inflammation [36]. Two recent trials have evaluated the effect of monoclonal antibodies on atherosclerosis regression. The GLAGOV trial reported the effectiveness of the PCSK9 inhibitor (evolocumab) compared with statin alone, on plaque regression at the LDL-C level of $36 \mathrm{mg} / \mathrm{dL}$, further confirming "the lower the better" theory [20]. The ODYSSEY J-IVUS trials showed that alirocumab treatment over 36 weeks

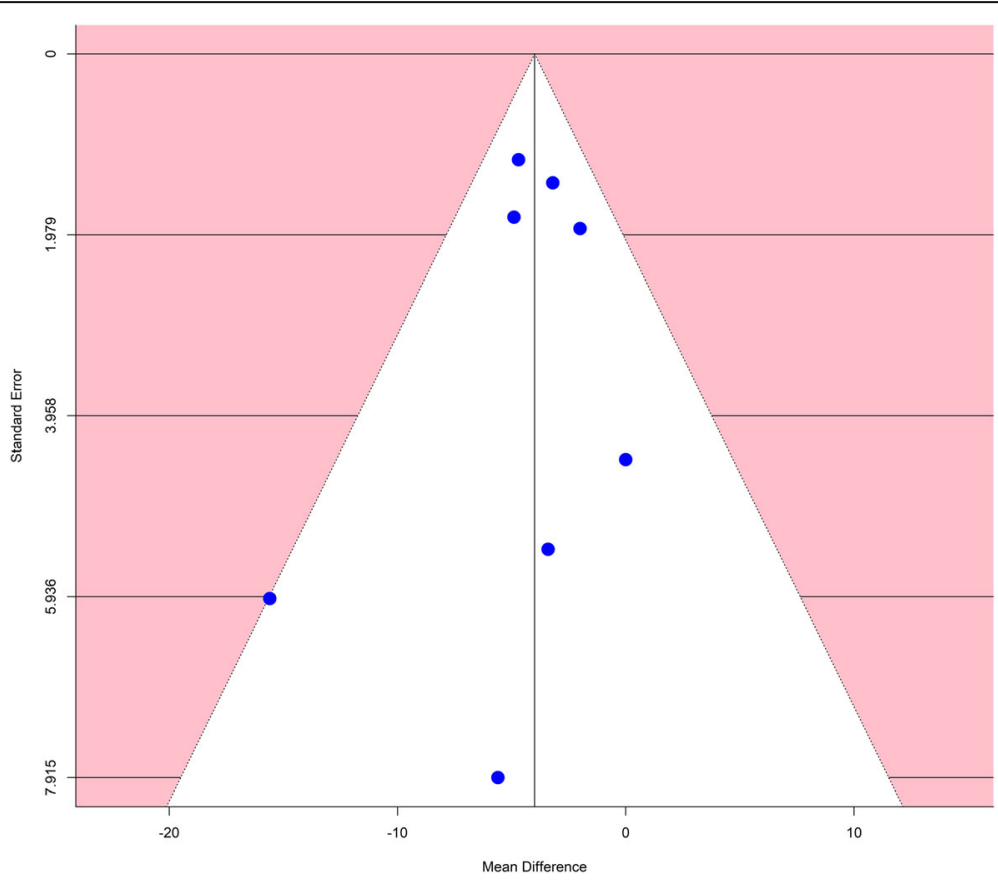

Fig. 6 Funnel plot to assess publication bias 


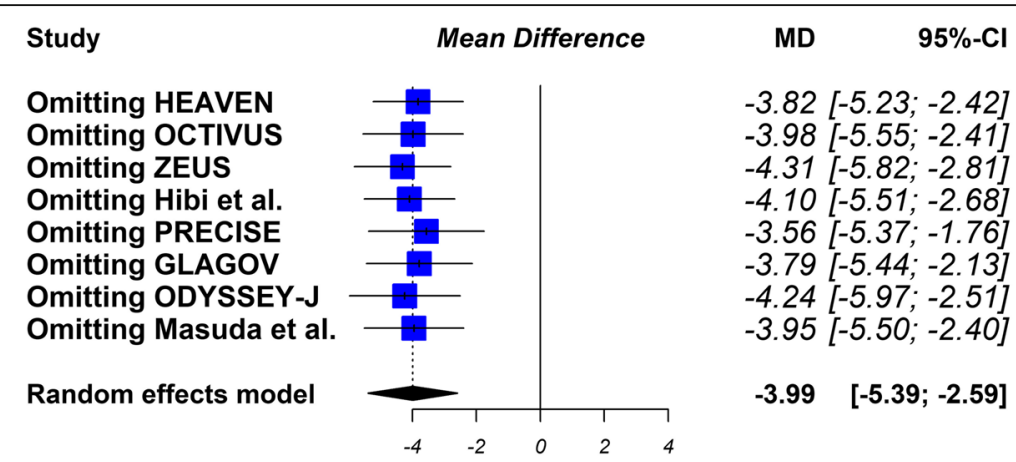

Fig. 7 Sensitivity analysis. After replicating the results of the meta-analysis, excluding in each step one of the studies included in the review, the results obtained are similar

resulted in a numerically greater but not statistically significant percentage reduction in TAV [21]. The lack of a statistically significant difference in the primary efficacy endpoint observed in this study needs to be considered in light of several specific factors of the study design, such as the limited sample size and the short duration of treatment period.

Consequently, it is essential to strengthen the evidence on these new medications. The addition of a PCSK9 inhibitor to a statin regimen has been shown to further reduce LDL-C levels by 43 to 64\% [37], and its use could increase considerably since in usual clinical practice, many patients do not reach the goals proposed by combining statins with ezetimibe [38]. Likewise, the latest published guidelines have recommended the use of ezetimibe and PCSK9 inhibitors as additional medications to reduce the residual risk of patients at higher risk [39, 40]. Therefore, we consider the evaluation of the impact of both drugs on the regression of atherosclerosis as a very important fact.

This is the first meta-analysis to demonstrate that the combination of statin and ezetimibe or PCSK9 inhibitors therapy is associated with a significantly greater reduction in TAV, compared with statin monotherapy.

Another point of this study is that it evaluates through a meta-regression analysis the effect of lipid levels reduction generated by dual lipid-lowering therapy on the regression of atherosclerosis.

A large body of evidence supports a central role for LDL-C lowering in the prevention of atherosclerotic cardiovascular disease [41]. It is proven that the process of atherosclerosis strongly depends on LDL-C, but whether or not this dependence is similar in statin regimens and dual therapy regimens is less defined $[17,18]$. It is therefore reasonable to think that the effects of the ezetimibestatin combination therapy can vary according to the patient sample (e.g. statin naïve versus statin pretreated patients; acute coronary syndrome versus chronic coronary disease), and time of assessment of outcome. In a subanalysis of the PRECISE-IVUS trial, the IVUS endpoints were compared according to the presence or absence of statin pretreatment [42]. The atorvastatin/ ezetimibe combination showed a significant stronger reduction in atheroma volume, compared with atorvastatin alone, in patients with statin pretreatment. Compensatory increase in cholesterol absorption observed in statin-treated patients might attenuate the inhibitory effects of statins on coronary plaque progression.

The results of this meta-analysis showed that with the lowest LDL-C levels achieved with dual lipid lowering therapy, a greater reduction in plaque volume was observed. These results suggested that the decrease in LDL-C itself would be more relevant than the mechanism that generates it. In that sense, a recent subanalysis of the PRECISE-IVUS study conducted in patients with acute coronary syndrome concluded that the regression of coronary atherosclerotic plaque was associated more with the decrease in LDL-C than with the established lipid-lowering therapy (high-intensity statins or combined therapy) [43].

The called "LDL hypothesis" assumes that reducing LDL-C levels, regardless of the means, should produce a corresponding reduction in cardiovascular events. An alternative theory, referred as "statin hypothesis", proposes that statins have a unique efficacy in atherosclerotic vascular disease that is not shared by other lipid-modifying agents. Considerable evidence supports the LDL hypothesis, including several epidemiologic studies and clinical trials of both statins and non-statin lipid-modifying agents. The Cholesterol Treatment Trialists' (CTT) meta-analysis, that included randomized trials of statins, found that, on average, a reduction of $1 \mathrm{mmol}$ per liter in LDL-C levels yields a consistent $23 \%$ reduction in the risk of major coronary events over 5 years [6]. Similarly, in the IMPROVE-IT and the FOURIER studies the extent of benefit afforded by the statin-ezetimibe or statin-evolocumab combination respectively, was consistent with that seen in the CTT meta-analysis, with 
a similar reduction in cardiovascular events according to the degree of LDL-C lowering [12, 29].

The non-HDL-C comprises cholesterol carried by all potentially atherogenic particles, is simpler, more convenient and more predictive than LDL-C [44]. The present study also evaluated the impact of this lipid marker on atheroma regression, showing similar findings to the C-LDL analysis.

The process of plaque regression by aggressive LDL-C lowering therapy could also stabilize the unstable plaque and reverse the positive remodeling of the vessel wall [45]. As combination therapy with a statin and either ezetimibe or PCSK9 inhibitors lowers LDL-C levels beyond that achieved with statin monotherapy, dual lipid-lowering treatment strategy may have additional protective cardiovascular effects [46]. The findings of this meta-analysis align with these concepts. At present, dual therapy is recommended to be administered in patients with high or very high cardiovascular risk who, despite maximum tolerated dose of statins, do not reach the recommended lipid targets. Both ezetimibe and PCSK9 inhibitors are usually well tolerated with few adverse effects. Continued therapy should be sustained in such cases.

\section{Limitations}

This meta-analysis presents several limitations. First, they are related with clinical heterogeneity (popular characteristics, different schemes of lipid-lowering therapy, different followup)and the number of patients included in most of the studies was low. In fact, the pathophysiological mechanisms involved in acute coronary syndrome are not exactly the same as in chronic coronary heart disease. However, the statistical heterogeneity was low and the results were robust when performing the sensitivity analysis, including when the sensitivity analysis was done only with randomized clinical trials. Second, the analysis included only trial-level data without having the individual data. Third, the meta-regression analysis was performed with 8 studies, when some authors suggest doing it with 10 or more. We consider that the number of studies evaluated approached the suggested number, being also the total of the available evidence at present. Likewise, metaregression in our study is a complement to the main result that is meta-analysis. Fourth, this study was not designed to assess the cost effectiveness of non-statin therapy. New studies in this area should be developed to answer this question. Finally, we did not perform the analysis with another primary endpoint, such as the percentage of atheroma volume (PAV), because these data was not informed in all the original publications.

\section{Conclusion}

This data suggest the addition of ezetimibe or PCSK9 inhibitors to statin therapy results in significantly increased regression of TAV. When the LDL-C and non-
HDL-C levels reached were lower, the observed effect on atherosclerosis regression was also greater. The process of plaque regression by aggressive LDL-C and nonHDL-C lowering therapy with non-statin drugs can occur. The decrease in LDL-C and non-HDL-C by themselves would be more relevant than the mechanism that generate it and would explain why using these drugs has an additional protective cardiovascular effect. Future lipid lowering drugs should also demonstrate their impact on the regression of atherosclerosis.

\section{Abbreviations \\ TAV: Atheroma volume; PCSK9: Proprotein convertase subtilisin kexin type 9; IVUS: Intravascular ultrasound; LDL-C: Low density lipoprotein cholesterol; non-HDL-C: Non-high-density-lipoprotein cholesterol; PAV: Percentage of atheroma volume}

\section{Acknowledgments \\ None.}

\section{Authors' contributions}

Walter Masson was the main coordinator of the project and was responsible for the study design. Walter Masson and Daniel Siniawski drafted the manuscript of the present paper. Melina Huerín was involved in the supervising of data collection and stratification. Martin Lobo and Juan Patricio Nogueira contributed to data assembly and analysis. Gerardo Masson contributed with manuscript revision. All authors contributed intellectually to this manuscript and have approved this final version.

\section{Funding}

No funding was received for the preparation of this study.

\section{Availability of data and materials}

The data in the current paper are publicly available since this a meta-analysis conducted on the basis of the cited literature.

Ethics approval and consent to participate

Not applicable.

\section{Consent for publication}

Not applicable.

\section{Competing interests}

The authors declare that they have no competing interests.

\section{Author details}

${ }^{1}$ Council of Epidemiology and Cardiovascular Prevention, Argentine Society of Cardiology, Azcuenaga 980, C1115AAD Buenos Aires, Argentina.

${ }^{2}$ Argentine Society of Lipids, Ambrosio Olmos 820, X5000JGQ Córdoba,

Argentina. ${ }^{3}$ Av. Dr. Luis Gutniski 3200, 3600 Formosa, Argentina.

Received: 12 January 2020 Accepted: 21 May 2020

Published online: 27 May 2020

\section{References}

1. Masson W, Siniawski D, Lobo M, Molinero G, Giorgi M, Huerín M. Association between LDL-C, non HDL-C, and Apolipoprotein B levels with coronary plaque regression. ArqBrasCardiol. 2015;105:11-9.

2. Nicholls SJ, Hsu A, Wolski K, Hu B, Bayturan O, Lavoie A, et al. Intravascular ultrasound-derived measures of coronary atherosclerotic plaque burden and clinical outcome. J Am Coll Cardiol. 2010;55:2399-407.

3. D'Ascenzo F, Agostoni P, Abbate A, Castagno D, Lipinski MJ, Vetrovec GW, et al. Atherosclerotic coronary plaque regression and the risk of adverse cardiovascular events: a meta-regression of randomized clinical trials. Atherosclerosis. 2013;226:178-85.

4. Taylor F, Huffman MD, Macedo AF, Moore THM, Burke M, Davey Smith G, et al. Statins for the primary prevention of cardiovascular disease. Cochrane Database Syst Rev. 2013;2013(1):CD004816. 
5. Cholesterol Treatment Trialists' (CTT) Collaboration, Baigent C, Blackwell L, Emberson J, Holland LE, Reith C, et al. Efficacy and safety of more intensive lowering of LDL cholesterol: a meta-analysis of data from 170,000 participants in 26 randomised trials. Lancet. 2010;376:1670-81.

6. Cholesterol Treatment Trialists' (CTT) Collaborators, Kearney PM, Blackwell L, Collins R, Keech A, Simes J, et al. Efficacy of cholesterol-lowering therapy in 18,686 people with diabetes in 14 randomised trials of statins: a metaanalysis. Lancet. 2008;371:117-25.

7. Nissen SE, Nicholls SJ, Sipahi I, Libby P, Raichlen JS, Ballantyne CM, et al. Effect of very high-intensity statin therapy on regression of coronary atherosclerosis: the ASTEROID trial. JAMA. 2006;295:1556-65.

8. Okazaki S, Yokoyama T, Miyauchi K, Shimada K, Kurata T, Sato H, et al. Early statin treatment in patients with acute coronary syndrome: demonstration of the beneficial effect on atherosclerotic lesions by serial volumetric intravascular ultrasound analysis during half a year after coronary event: the ESTABLISH study. Circulation. 2004;110:1061-8.

9. Hiro T, Kimura T, Morimoto T, Miyauchi K, Nakagawa Y, Yamagishi M, et al. Effect of intensive statin therapy on regression of coronary atherosclerosis in patients with acute coronary syndrome: a multicenter randomized trial evaluated by volumetric intravascular ultrasound using pitavastatin versus atorvastatin (JAPAN-ACS [JAPAN assessment of pitavastatin and atorvastatin in acute coronary syndrome] study). J Am Coll Cardiol. 2009;54:293-302.

10. Nicholls SJ, Ballantyne CM, Barter PJ, Chapman MJ, Erbel RM, Libby P, et al. Effect of two intensive statin regimens on progression of coronary disease. N Engl J Med. 2011;365:2078-87.

11. Takayama T, Hiro T, Yamagishi M, Daida H, Hirayama A, Saito S, et al. Effect of rosuvastatin on coronary atheroma in stable coronary artery disease: multicenter coronary atherosclerosis study measuring effects of rosuvastatin using intravascular ultrasound in Japanese subjects (COSMOS). Circ J. 2009; 73:2110-7.

12. Cannon CP, Blazing MA, Giugliano RP, McCagg A, White JA, Theroux P, et al. EzetimibeAdded to StatinTherapyafterAcuteCoronarySyndromes. N Engl J Med. 2015;372:2387-97.

13. Schwartz GG, Steg PG, Szarek M, Bhatt DL, Bittner VA, Diaz R, et al. Alirocumab and cardiovascular OutcomesafterAcuteCoronarySyndrome. N Engl J Med. 2018:379:2097-107.

14. Kovarnik T, Mintz GS, Skalicka H, Kral A, Horak J, Skulec R, et al. Virtual histology evaluation of atherosclerosis regression during atorvastatin and ezetimibe administration: HEAVEN study. Circ J. 2012;76:176-83.

15. Hougaard $M$, Hansen $H S$, Thayssen $P$, Antonsen $L$, Junker $A$, Veien $K$, et al. Influence of ezetimibe in addition to high-dose atorvastatin therapy on plaque composition in patients with ST-segment elevation myocardial infarction assessed by serial: intravascular ultrasound with iMap: the OCTIVUS trial. Cardiovasc Revasc Med. 2017;18:110-7.

16. Nakajima N, Miyauchi K, Yokoyama T, Ogita M, Miyazaki T, Tamura H, et al. Effect of combination of ezetimibe and a statin on coronary plaque regression in patients with acute coronary syndrome: ZEUS trial (eZEtimibe ultrasound study). IJC Metab Endocr. 2014;3:8-13.

17. Hibi K, Sonoda S, Kawasaki M, Otsuji Y, Murohara T, Ishii H, et al. Effects of Ezetimibe-statin combination therapy on coronary atherosclerosis in acute coronary syndrome. Circ J. 2018;82:757-66.

18. Tsujita K, Sugiyama S, Sumida H, Shimomura H, Yamashita T, Yamanaga K, et al. Impact of dual lipid-lowering strategy with Ezetimibe and atorvastatin on coronary plaque regression in patients with percutaneous coronary intervention: the multicenter randomized controlled PRECISE-IVUS trial. J Am Coll Cardiol. 2015;66:495-507.

19. Masuda J, Tanigawa T, Yamada T, Nishimura Y, Sasou T, Nakata T, et al. Effect of combination therapy of ezetimibe and rosuvastatin on regression of coronary atherosclerosis in patients with coronary artery disease. Int Heart J. 2015:56:278-85.

20. Nicholls SJ, Puri R, Anderson T, Ballantyne CM, Cho L, Kastelein JJP, et al. Effect of Evolocumab on progression of coronary disease in statin-treated patients: the GLAGOV randomized clinical trial. JAMA. 2016:316:2373-84

21. Ako J, Hibi K, Tsujita K, Hiro T, Morino Y, Kozuma K, et al. Effect of Alirocumab on coronary atheroma volume in Japanese patients with acute coronary syndrome - the ODYSSEY J-IVUS trial. Circ J. 2019;83:2025-33.

22. Mirzaee S, Thein PM, Nogic J, Nerlekar N, Nasis A, Brown AJ. The effect of combined ezetimibe and statin therapy versus statin therapy alone on coronary plaque volume assessed by intravascular ultrasound: A systematic review and meta-analysis. J Clin Lipidol. 2018;12:1133-1140.e15.
23. Liberati A, Altman DG, Tetzlaff J, Mulrow C, Gøtzsche PC, loannidis JPA, et al. The PRISMA statement for reporting systematic reviews and meta-analyses of studies that evaluate healthcare interventions: explanation and elaboration. BMJ. 2009:339:b2700.

24. Wan X, Wang W, Liu J, Tong T. Estimating the sample mean and standard deviation from the sample size, median, range and/or interquartile range. BMC Med Res Methodol. 2014;14:135.

25. Bukoh MX, Siah C-JR. A systematic review and meta-analysis on the structured handover interventions in improving patient safety outcomes. $J$ Nurs Manag. 2020;28(3):744-55.

26. Law M, Jackson D, Turner R, Rhodes K, Viechtbauer W. Two new methods to fit models for network meta-analysis with random inconsistency effects. BMC Med Res Methodol. 2016;16:87.

27. Savarese G, De Ferrari GM, Rosano GMC, Perrone-Filardi P. Safety and efficacy of ezetimibe: a meta-analysis. Int J Cardiol. 2015;201:247-52.

28. Kalra S. Proprotein Convertase Subtilisin Kexin 9 (PCSK9) inhibition: a Lipocrinologic review. J Assoc Physicians India. 2018;66:70-2.

29. Sabatine MS, Giugliano RP, Keech AC, Honarpour N, Wiviott SD, Murphy SA, et al. Evolocumab and ClinicalOutcomes in Patientswith cardiovascular disease. N Engl J Med. 2017;376:1713-22.

30. Nissen SE, Tuzcu EM, Schoenhagen P, Brown BG, Ganz P, Vogel RA, et al. Effect of intensive compared with moderate lipid-lowering therapy on progression of coronary atherosclerosis: a randomized controlled trial. JAMA. 2004;291:1071-80.

31. Kastelein JJP, Akdim F, Stroes ESG, Zwinderman AH, Bots ML, Stalenhoef $\mathrm{AFH}$, et al. Simvastatinwithorwithoutezetimibe in familialhypercholesterolemia. N Engl J Med. 2008;358:1431-43.

32. Huang Y, Li W, Dong L, Li R, Wu Y. Effect of statin therapy on the progression of common carotid artery intima-media thickness: an updated systematic review and meta-analysis of randomized controlled trials. J AtherosclerThromb. 2013;20:108-21.

33. Biondi-Zoccai G, Mastrangeli S, Romagnoli E, Peruzzi M, Frati G, Roever L, et al. What we have learned from the recent meta-analyses on diagnostic methods for atherosclerotic plaque regression. CurrAtheroscler Rep. 2018; 20(1):2.

34. Cheng JM, Oemrawsingh RM, Garcia-Garcia HM, Boersma E, van Geuns R-J, Serruys PW, et al. PCSK9 in relation to coronary plaque inflammation: results of the ATHEROREMO-IVUS study. Atherosclerosis. 2016;248:117-22.

35. Cesaro A, Bianconi V, Gragnano F, Moscarella E, Fimiani F, Monda E, et al. Beyond cholesterol metabolism: the pleiotropic effects of proprotein convertase subtilisin/kexin type 9 (PCSK9). Genetics, mutations, expression, and perspective for long-term inhibition. Biofactors. 2020;30. https://doi.org/ 10.1002/biof.1619.

36. Sahebkar A, Di Giosia P, Stamerra CA, Grassi D, Pedone C, Ferretti G, et al. Effect of monoclonal antibodies to PCSK9 on high-sensitivity C-reactive protein levels: a meta-analysis of 16 randomized controlled treatment arms. Br J Clin Pharmacol. 2016;81:1175-90.

37. Del Pinto R, Grassi D, Properzi G, Desideri G, Ferri C. Low density lipoprotein (LDL) cholesterol as a causal role for atherosclerotic disease: potential role of PCSK9 inhibitors. High Blood Press Cardiovasc Prev. 2019:26:199-207.

38. Siniawski D, Masson W, Rossi E, Damonte J, Halsband A, Pizarro R. Eligibility for the indication of PCSK9 inhibitors according to the recommendations of different scientific societies. Medicina (B Aires). 2019;79:104-10.

39. Grundy SM, Stone NJ, Guideline Writing committee for the 2018 cholesterol Guidelines. 2018 cholesterol clinical practice guidelines: synopsis of the 2018 American Heart Association/American College of Cardiology/ multisociety cholesterol guideline. Ann Intern Med. 2019;170:779-83.

40. Mach F, Baigent C, Catapano AL, Koskinas KC, Casula M, Badimon L, et al. 2019 ESC/EAS Guidelines for the management of dyslipidaemias: lipid modification to reduce cardiovascular risk. Eur Heart J. 2020;41(1):111-88.

41. Whayne TF. Low-density lipoprotein cholesterol (LDL-C): how low? CurrVascPharmacol. 2017;15:374-9.

42. Tsujita K, Yamanaga K, Komura N, Sakamoto K, Sugiyama S, Sumida H, et al. Synergistic effect of ezetimibe addition on coronary atheroma regression in patients with prior statin therapy: subanalysis of PRECISE-IVUS trial. Eur J PrevCardiol. 2016;23:1524-8.

43. Tsujita K, Yamanaga K, Komura N, Sakamoto K, Sugiyama S, Sumida H, et al. Lipid profile associated with coronary plaque regression in patients with acute coronary syndrome: subanalysis of PRECISE-IVUS trial. Atherosclerosis. 2016;251:367-72. 
44. Su X, Kong Y, Peng D. Evidence for changing lipid management strategy to focus on non-high density lipoprotein cholesterol. Lipids Health Dis. 2019; 18:134.

45. Daida H, Dohi T, Fukushima Y, Ohmura H, Miyauchi K. The goal of achieving atherosclerotic plaque regression with lipid-lowering therapy: insights from IVUS trials. J AtherosclerThromb. 2019;26:592-600.

46. Gragnano F, Calabrò P. Role of dual lipid-lowering therapy in coronary atherosclerosis regression: evidence from recent studies. Atherosclerosis. 2018;269:219-28.

\section{Publisher's Note}

Springer Nature remains neutral with regard to jurisdictional claims in published maps and institutional affiliations.

Ready to submit your research? Choose BMC and benefit from:

- fast, convenient online submission

- thorough peer review by experienced researchers in your field

- rapid publication on acceptance

- support for research data, including large and complex data types

- gold Open Access which fosters wider collaboration and increased citations

- maximum visibility for your research: over $100 \mathrm{M}$ website views per year

At $\mathrm{BMC}$, research is always in progress.

Learn more biomedcentral.com/submissions 